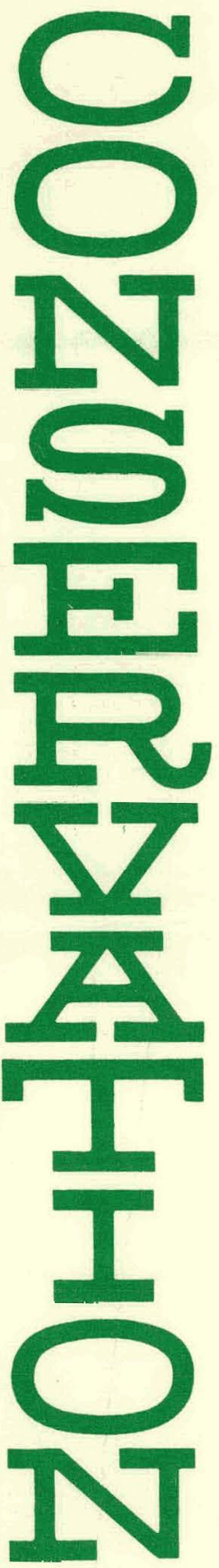

DEVELOPMENT OF A PRACTICAL PHOTOCHEMICAL ENERGY STORAGE SYSTEM

Quarterly Report

Richard R. Hautala

Charles R. Kutal

Date Published-June 15, 1977

Work Performed Under Contract No. EY-76-S-09-0893

University of Genrgia

Department of Chemistry

Athens, Georgia

\title{
ENERGY RESEARCH AND
}

HASTER

\section{DEVELOPMENT ADMINISTRATION}

Division of Energy Storage Systems 


\section{DISCLAIMER}

This report was prepared as an account of work sponsored by an agency of the United States Government. Neither the United States Government nor any agency Thereof, nor any of their employees, makes any warranty, express or implied, or assumes any legal liability or responsibility for the accuracy, completeness, or usefulness of any information, apparatus, product, or process disclosed, or represents that its use would not infringe privately owned rights. Reference herein to any specific commercial product, process, or service by trade name, trademark, manufacturer, or otherwise does not necessarily constitute or imply its endorsement, recommendation, or favoring by the United States Government or any agency thereof. The views and opinions of authors expressed herein do not necessarily state or reflect those of the United States Government or any agency thereof. 


\section{DISCLAIMER}

Portions of this document may be illegible in electronic image products. Images are produced from the best available original document. 


\title{
NOTICE
}

This report was prepared as an account of work sponsored by the United States Government. Neither the United States nor the United States Energy Research and Development Administration, nor any of their employees, nor any of their contractors, subcontractors, or their employees, makes any warranty, express or implied, or assumes any legal liability or responsibility for the accuracy, completeness or usefulness of any information, apparatus, product or process disclosed, or represents that its use would not infringe privately owned rights.

This report has been reproduced directly from the best available copy.

Available from the National Technical Information Service, U. S. Department of Commerce, Springfield, Virginia 22161

\author{
Price: Paper Copy $\$ 3.50$ (domestic) \\ $\$ 6.00$ (foreign) \\ Microfiche $\$ 3.00$ (domestic) \\ $\$ 4.50$ (foreign)
}




\section{DEVELOPMENT OF A PRACTICAL PHOTOCHEMICAL \\ ENERGY STORAGE SYSTEM \\ Quarterly Report}

Richard R. Hautala and Charles R. Kutal

June 15,1977

UNDER CONTRACT E(38-1)-893

PREPARED FOR

ENERGY RESEARCH AND DEVELOPMENT ADMINISTRATION

This report was prepared as an account of work

qunnsored by the United States Government. Neither

the United States nor the Administration, nor any of Research and Developmest Any of their contractors, their emplos, or their employees. makes any warranty, express or implied, or assumes any legal tiability or responsibility for the accuracy, completeness or usefulness of any information, apparalus, product or
process disclosed, or tepresents that its use would not infringe privately owned rights.

Department of Chemistry

University of Georgia

Athens, Georgia 30602 
Recent work has involved the analysis of the functionalized polymer primarily being used in our photochemical studies. This polymer, referred to as $N$-polymer in earlier reports, 1,2 was prepared by the following reaction sequence using a macroreticular polystyrence resin which is cross-linked with divinylbenzene.
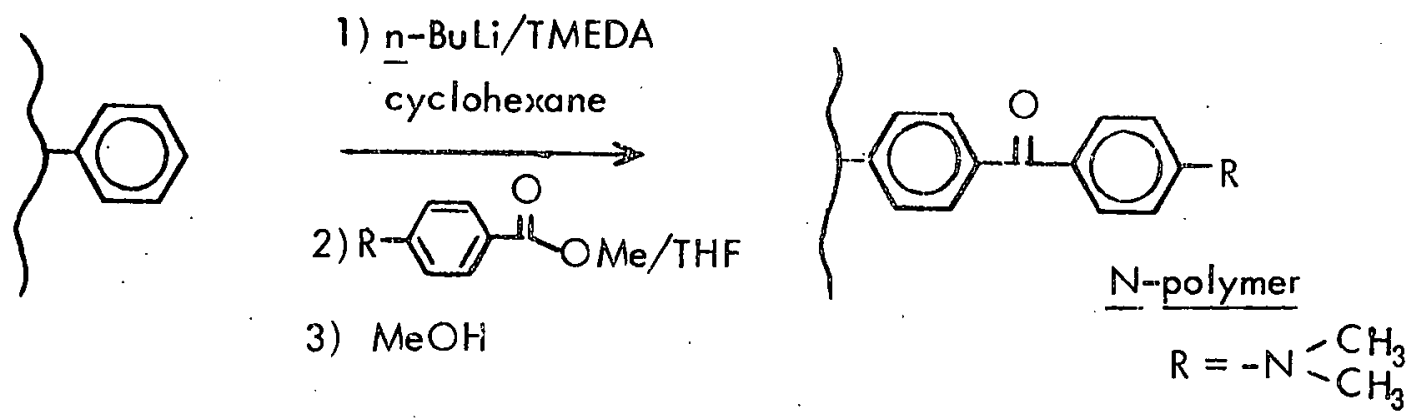

Analysis indicated $0.343 \mathrm{meq} / \mathrm{gram}$ of nitrogen which is a $3.7 \%$ ring substitution. The nitrogen content alone does not verify the structure of the polymer, for the synthetic conditions allow "site-site" interaction. The lithiared polystyrene after initially attacking the ester could conceivably attack again to give the precursor to a tertiary alcohol.

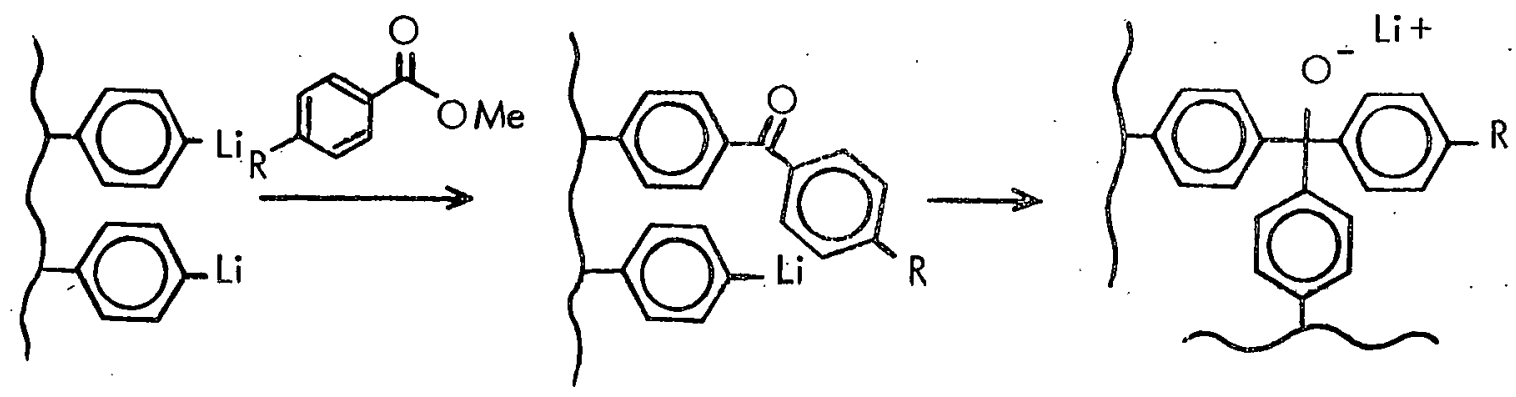

The oxime will be formed to determine if alcohol formation is a significant side reaction. Ultimately if the analysis procedure is satisfactory, the procedure will also be applied to $\mathrm{N}$-polymer used in the prototype to determine whether or not any change in the resin has ocurred upon extensive photolysis.

Work involving 4,4-(N,N-dimethyl)aminobenzophenone as a sensitizer for quadricyclene formation demonstrates that the maximum (extrapolated) efficiency of 
sensitization is a function of its concentration (all absorbances $\geq 2$ ). This could be due to self-quenching of the triplet state at high concentrations.

This effect has been surveyed using a functionalized polymer support. By
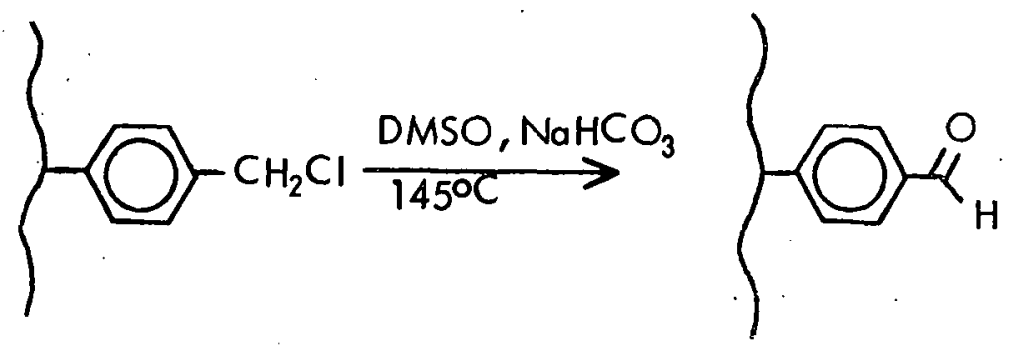

limiting the reaction times, the amount of ring substitution was varied from 5 to 10 percent. The substitution was determined by $\mathbb{R}$ which allows comparison of the alde yde stretching frequency at $1690 \mathrm{~cm}^{-1}$ versus one of the stronger bands from the polystyrene. Initial studies show that the quantum yield for production of quadricyclene is fairly. constant over this concentration range.

\section{POLYMERIC INORGANIC SENSITIZERS}

During the past quarter we have continued our investigation ${ }^{2}$ of the promising sensitizer, $\operatorname{Ir}(\text { bipy })_{2}\left(\right.$ bipy' $\left.^{\prime}\right) \mathrm{OH}^{+2}$. The +2 charge on this compound facilitates its immobilization onto a sulfonated polystyrene-divinylbenzene (20\% crosslinked) resin . A sample of the polymer bound sensitizer in contact with a $0.5 \mathrm{M}$ norbornadiene-benzene

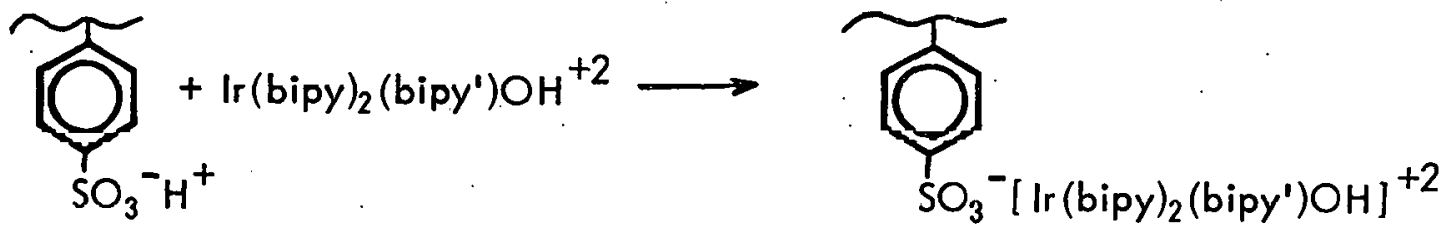

solution was irradiated with $366 \mathrm{~nm}$ light, resulting in a quantum yield for quadricyclene production of 0.06 . By comparison, the quantum yield obtained upon irradiating the sensitizer in homogeneous solution is $\sim 0.20$. The reason for the decreased efficiency 
is not apparent at this point, but we have noted an apparent inverse relationship between quantum yield and the extent of loading of the sensitizer on the polymer. Further work is underway to explain this behavior as well as to better characterize the polymeric sensitizer itself.

We have also conducted some sensitization studies of the related compound, $\operatorname{Ir}(\text { bipy })_{2}\left(\right.$ bipy' $\left.^{\prime}\right) \mathrm{OH}_{2}^{+3}$, in methanol-benzene solution. Thus at $366 \mathrm{~nm}$ the quantum yield for quadricyclene production is 0.7 , whereas at $406 \mathrm{~nm}$ the value is $0.2-0.3$. These high efficiencies, as well as the ability to absorb light out to $\sim 480 \mathrm{~nm}$, make $\operatorname{Ir}(\text { bipy })_{2}$ (bipy' $) \mathrm{OH}_{2}^{+3}$ an attractive candidate for further study. During the next quarter, we plan to immobilize the compound onto the sulfonated resin and determine its sensitization efficiency under a variety of conditions.

\section{CATALYSIS OF THE CONVERSION OF NORBORNADIENE TO QUADRICYCLANE}

\section{A. Polymer-Supported Catalysts}

During this quarter kinetic studies have continued on both the polystyreneanchored cobalt(II) tetraarylporphyrin catalysts and the polymer-anchored palladium (II) chloride complexes obtained from palladium (II) chloride and diphenylphosphinated polystyrene in acetonitrile solution. Many of these results are summarized in the attached manuscript (Appendix A) entitled "Attached Metal Complex Catalysts for a Solar Energy Storage System". This manuscript was prepared for the Division of Petroleum Chemistry of the American Chemical Society in connection with presentation of this work at a symposium on the "Design and Characterization of Attached Metal Complex Catalysts". at the National Meeting of the American Chemical Society in Chicago at the end of August, 1977.

Since the preparation of this manuscript further work has been done on improving the preparation of the sulfonamide-linked polystyrene-anchored cobalt(II) tetraphenylporphyrin (structure IV in Appendix A). In the near future we plan to prepare samples of this 
polymer-anchored cobalt complex with different degrees of loading in onder to see the effects of metal content on the catalytic activity and the susceptibility towards deactivation:

\section{B. Triphenylcyclopropenylnickel Catalysts}

The previous quarterly report ${ }^{2}$ discussed in detail various structure-activity relationships in the series of triphenylcyclopropenylnickel complexes. During this quarter some detailed studies were carried out of the kinetics of the conversion of quadricyclane to norbornadiene catalyzed by $\left[\left(\mathrm{C}_{6} \mathrm{H}_{5}\right)_{3} \mathrm{C}_{3} \mathrm{Ni}(\mathrm{CO}) \mathrm{Cl}\right]_{2}$.

A dichloromethane solution of a measured quantity of $\left[\left(\mathrm{C}_{6} \mathrm{H}_{5}\right)_{3} \mathrm{C}_{3} \mathrm{Ni}(\mathrm{CO}) \mathrm{C}\right.$; ( 2 to $15 \mathrm{mg}$.) was treated with a dichloromethane solution containing a measured qu ntity of quadricyclane. The reaction temperature was controlled by an external bath thermostatted at $30 \pm 0.1^{\circ} \mathrm{C}$ or by an ice bath at 0 to $0.5^{\circ} \mathrm{C}$. At various time intervals $1 \mathrm{ml}$. of the homogeneous reaction solution was withdrawn and analyzed by gas chromatography using a $1 / 8$ " $\times 6^{\prime}$ to $10^{\prime} 7.8 \%$ GE SF-96 on Chromosorb W column with a $60 \mathrm{ml} . / \mathrm{min}$. nitrogen flow and a flame ionization detector. Concentrations were determined by the peak area ratios of quadricyclane and norbornadiene to the methylene chloride.

The most significant results from these kinetic studies are summarized below.

(1) Quadricyclane concentration versus time at various concentrations of the nickel catalyst.

Plotting In [quadricyclane] versus time gave a straight line at the beginning of the reaction corresponding to a pseudo first order reaction. However, after several minutes these straight lines began to bend upward indicating retardation of the reaction by products from the reaction or from decomposition of the catalyst. This retardation began at about 2 minutes in reactions performed at $30^{\circ} \mathrm{C}$ and at about 10 minutes in 
reactions performed at $0^{\circ} \mathrm{C}$. In both cases the onset of the rate retardation corresponded to similar points of conversion of quadricyclane to norbornadiene.

(2) Quadricyclane concentration versus time at various concentrations of quadricyclane.

Again the initial straight line plot of In[quadricyclane] versus time curved upward after several minutes indicating a retardation of the reaction rate. The smaller the quadricyclane concentration the later the onset of this retardation.

(3) Quadricyclane concentration versus time in the presence of excess norbornadiene.

Increasing amounts of added excess norbornadiene result in increasing retardation of the reaction rate. In $7 M$ norbornadiene the reaction was inhibited completely.

These observations suggest that norbornadiene deactivates the triphenylcyclopropenylnickel catalyst apparently by blocking required coordination positions. A similar deactivating effect was also observed by coordinating solvents such as methanol and teirahydrofuran. In any case the actual nickel catalyst in these reactions does not appear to be the triphenylcyclopropenylnickel derivative since unchanged $\left.\left[\left(\mathrm{C}_{6} \mathrm{H}_{5}\right)_{3} \mathrm{C} \mathrm{Ni} \mathrm{NO}\right) \mathrm{Cl}\right]_{2}$ could not be recovered from the reaction solution after completion of the catalytic reaction.

\section{Trigonal Prismatic Molybdenum Catalysts}

Some initial kinetic studies on the conversion of quadricyclane to norbornadiene catalyzed by the molybdenum complex $\left[\left(\mathrm{CF}_{3}\right)_{2} \mathrm{C}_{2} \mathrm{~S}_{2}\right]_{3} \mathrm{Mo}(\mathrm{l})$ were performed. Straight line plots of $\ln$ [quadricyclane] versus time were obtained in several cases. This catalyst system appeared to be less sensitive towards deactivation by either oxidation or norbornadiene complexation than the other catalysts investigated. However, there was some evidence for side reactions leading to apparently polymeric materials. Further studies on this rather intriguing system are required before definite conclusions can be drawn. 


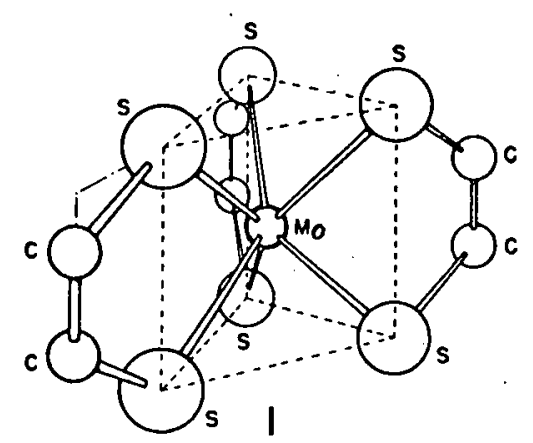

$\mathrm{CF}_{3}$ groups not shown

D. Miscellaneous

The following paper was piesenled by R. B. King at the Fifth INorth Amer' can Meeting of the Catalysis Society, April, 1977, in Pittsburgh, Pennsylvania:

R. B. King, E. M. Sweet, R. M. Hanes, and S. Ikai, "Catalysis in a Solaı Energy Storage System."

\section{PROTOTYPE SYSTEMS}

The prototype system described in the 1976-1977 annual report has been tested with the following results:

Energy Storage step: A solution of $50 \mathrm{ml}$. of benzene and $150 \mathrm{ml}$. of norbornadiene was irradiated for $440 \mathrm{hr}$. in the presence of a polymer-supported p-dimethylaminobenzophenone sensitizer. The final mixture contained $143 \mathrm{ml}$. of quadricyclane (by v.p.c.).

Energy release step: The solution was pumped $(2.5 \mathrm{ml} / \mathrm{min}$.) through a $1 / 4 " 1 \times 1 \mathrm{ft}$. catalyst bed packed with carboxamide-linked polystyrene-supported cobalt (II) porphyrin. The catalytic reactor was immersed in $750 \mathrm{ml}$. of water at $23^{\circ} \mathrm{C}$. During a period of $1 \mathrm{hr}$. Ihis water was heated to $44^{\circ} \mathrm{C}$

Energy released: $\left(21^{\circ} \mathrm{C}\right.$ temperature rise $) \times(0.75 \mathrm{kcal} . / \mathrm{deg} . \mathrm{C})=15.75 \mathrm{kcal}$.

Energy available: $(140 \mathrm{~g}$. quadricyclane $) \times(0.25 \mathrm{kcal} . / \mathrm{g})=.35 \mathrm{kcal}$.

Percent available energy released: $\frac{15.75}{35} \times 100=45 \%$ 
The $440 \mathrm{hr}$. (2 $1 / 2$ week) reaction time for the conversion of norbornadiene to quadricyclane made the use of this system impractical for the evaluation of its stability towards repeated recycling. Therefore this solar energy storage prototype was modified so that the photoreactor portion consisted of a flat face $10 \mathrm{~cm}$. cell with a $4 \mathrm{~mm}$. path length irradiated by two 100 watt medium pressure mercury flood lamps. The results from the evaluation of this modified solar energy system prototype are as follows:

Energy storage step: Norbornadiene $(60 \mathrm{ml})$ was pumped through this modified photochemical reactor at $1 \mathrm{ml} . / \mathrm{min}$. for $262 \mathrm{hr}$. using the same polymer-supported sensitizer. The final mixture contained $39 \mathrm{ml}$. of quadricyclane and $21 \mathrm{ml}$. of norbornadiene (by v.p.c.).

Energy release step: The solution was pumped $(1 \mathrm{ml} . / \mathrm{min}$.) through the $1 / 4 " \times 1 \mathrm{ft}$. catalyst bed packed with the same cobalt catalyst. The catalytic reactor was immersed in $750 \mathrm{ml}$. of water at $21.5^{\circ} \mathrm{C}$. During a period of $75 \mathrm{~min}$. this water was heated to $27^{\circ} \mathrm{C}$. Energy released: $\left(5.5^{\circ} \mathrm{C}\right.$ temperature rise $) \times(0.75 \mathrm{kcal} . / \mathrm{deg} . \mathrm{C})=4.125 \mathrm{kcal}$. Energy available: $\quad(39 \mathrm{~g}$. quadricyclane $) \times(0.25 \mathrm{kcal} . / \mathrm{g})=.9.75 \mathrm{kcal}$. Percent available energy released: $\frac{4.125}{9.75} \times 100=42 \%$ 


\section{REFERENCES}

I. Quarterly report for ERDA Contract E(38-1)-893, September 15, 1976.

2. Quarterly report for ERDA Contract E(38-1)-893, March 15, 1977. 


\title{
APPENDIX A
}

\section{ATTACHED METAL COMPLEX CATALYSTS FOR A SO LAR ENERGY STORAGE SYSTEM}

\author{
R. B. King, E. M. Sweet, and R.M. Hanes
}

Department of Chemistry, University of Georgia, Athens, Georgia 30602

$x \times x \times x \times x \times x \times x \times x \times x \times x \times x \times$

The following two types of polystyrene-anchored transition metal derivatives were found to be effective catalysts for the exothermic conversion of quadricyclane to norbornadiene in the energy-release step of a photochemical energy storage cycle:

(1) cobalt (II) tertraarylporphyrin derivatives linked to polystyrene through sulfonamido or carboxamido bridges; (2) polymer-anchored palladium (II) chloride complexes obtained from palladium(II) chloride and diphenylphosphinated polystyrene in acetonitrile solution. Kinetic data for the conversion of quadricyclane to norbornadiene by each of these two types of catalysts indicate that the cobalt catalysts are more active than the palladium catalysts. Furthermore, the polystyrene-anchored phosphine palladium (II) chloride catalyst is about 1000 times less active than the soluble monomeric catalyst $\left[\left(\mathrm{C}_{6} \mathrm{H}_{5}\right)_{3} \mathrm{P}\right]_{2} \mathrm{PdCl}_{2}$. The cobalt catalyst appears to be subject to deactivation through oxidation whereas the palladium catalyst appears to be subject to deactivation through complex formation with norbornadiene.

$x \times x \times x \times x \times x \times x \times x \times x \times x \times x \times$ 
introduction

The use of photochemical reactions to generate kinetically stable products of high energy content provides an exceedingly attractive fuel source since a virtually irexhaustible source of energy (sunlight) is converted into a usable form with no net consumption of resources. A promising method of this type for storing energy from sunlight is based on the photosensitized conversion of norbornadiene (I) to quadricyclane (II).

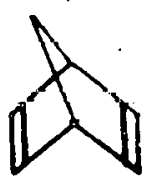

1
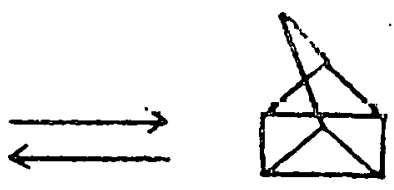

11

A device based on this reaction requires two steps: (1) Energy storage through the sensitized photolysis of norbornadiene (I) to quadricyclane (II) in an endothermic reaction; (2) Energy release through the catalyzed reconversion of quadricyclane (II) to norbornadiene (I) in an exothermic reaction. Sensitizers for the first step must absorb strongly in the region of available solar energy, be thermally and photochemically stable, and, of course, effect efficiently the desired sensitization. Ideal catalysts for the reverse reaction must also meet stringent criteria including long term stability as well as effecting rapid and clean conversions. Intraduction of the sensitizer and catalyst onto separate polymeric supports facilitates the construction of an actual device by keeping the sensitizer and catalyst apart. An energy storage device based on these principles could result in the practical use of solar energy for heating buildings and related applications.

This poper discusses research at the University of Georgia directed towards the development of suitable polystyrene-anchored metal complex catalysts for the conversicn of quadricyclane to norbornadiene in the energy-release step of the solar energy storage system outlined above.

When this research program was initiated in 1975 the only catalysts known to effect the conversion of quadricyclane to norbornadiene we re discrete molecular square planar complexes including particularly those of rhodium (I), nickel(II), ${ }^{3}$ cobalt(II), ${ }^{3}$ iron (II), ${ }^{3}$ and palladium(II), ${ }^{2,4}$. Catalysts for related metal-catalyzed openings of other 
strained ring systems such as bicyclobutanes, ${ }^{5-10}$ bicyclopentanes, 11,12 methylenecyclopropanes, $13,14,15,16$ cubanes, ${ }^{17}$ bishomocubyl derivatives, ${ }^{18}$ cuneanes, ${ }^{17}$ and other combinations of fused cyclobutane rings 19,20 were then limited to similar nickel (0), rhodium (I), palladium (II), and silver (I) derivatives. Methods for anchioring these catalytically active systems onto a polymeric matrix to give systems retaining the desired catalytic activity and stable towards leaching of the catalytically active metal were not obvious from the published work available at that time. Since 1975 the research work at the University of Georgia has resulted in the development of polymer-anchored catalysts for the conversion of quadricyclane to norbornadiene containing the following structural features: (1) Cobalt (II) tetraarylporphyrin derivatives linked to polystyrene through appropriate substituents on the phenyt rings; (2) Palladium (II) chloride complexes of diphenylphosphinated polystyrene. The preparation and catalytic properties of these two different types of attached metal complex catalysts are described in this paper.

\section{Polymer-anchored Cobalt (II) Porphyrin Catalysts}

The demonstrated 3,21 high catalytic activity of cobalt (II) porphyrins for the conversion of quadricyclane to norbornadiene coupled with the existence of known methods 22 for chemically anchoring cobalt (II) porphyrins onto polystyrene made such materials attractive candiates for polymer-anchored catalysts in the photochemical energy storage system. We therefore prepared the three polystyrene-anchored cobalt (II) tetraarylporphyrins schematically represented below as structures III, IV, and V (Poly = polymer, $X=$ terminal group). All three of these polymers were shown to be active catalysts for the conversion of quadricyclane to norbornadiene. In qualitative experiments all three polymers converted quadricyclane to norbornadiene so rapidly that pure quadricyclane boiled vigorously when poured onto the polymer. Preliminary quantitative kinetic experiments on the carboxamido-linked polymer $V$ are described later in this paper. 


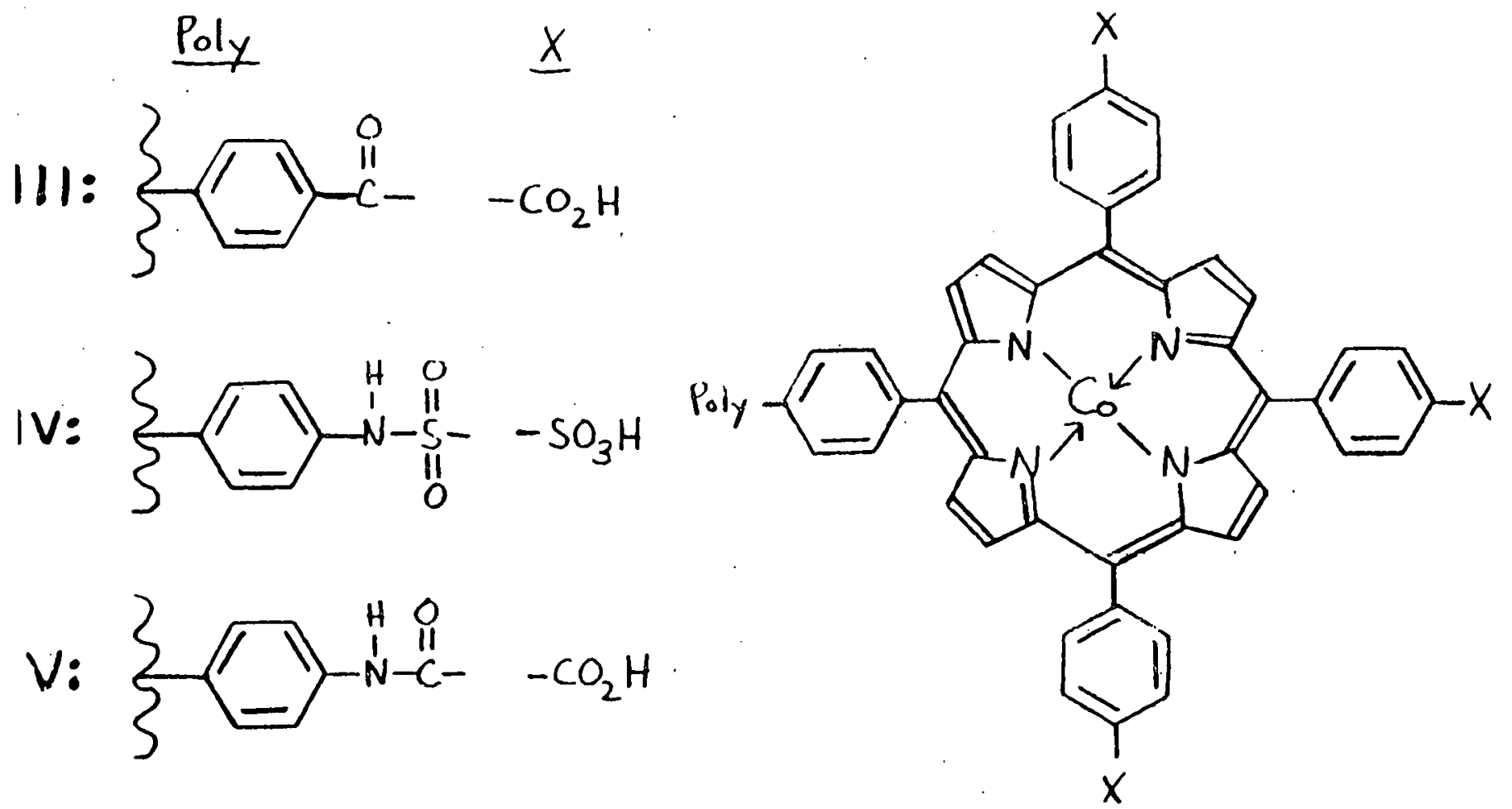

For the preparation of the polymers $I I I$ and $V$ the tetra ( $p$-carboxyphenyl)porphyrin. obtained from $p$-carboxybenzaldehydeand pyrrole by a published procedure ${ }^{23}$ was first converted to tetra ( $p$-chlorocarbonylphenyl)porphyrin by treatment with thionyl chloride. The ketone-linked polymer III was then obtained by a Friedel-Crafts reaction of the tetra ( $p$-chlorocarbonylphenyl)porphyrin with polystyrene followed by introduction of the cobalt with cobalt (II) acetate in boiling acetic acid. The carboxamide-linked polymer $V$ was obtained from tetra ( $p$-chlorocarbonylphenyl)porphyrin by treatment with aminopolystyrene in tetrahydrofuran solution in the presence of excess triethylamine followed by introduction of the cobalt with cobalt (II) acetate. Analysis of this polymer indicated $0.44 \%$ cobalt which is approximately twice the metal concentration achieved by Rollman. 22 For the preparation of the sulfonamide-linked polymer IV the reported ${ }^{24}$ ammonium salt of tetra ( $p$-suifonatophenyl)porphyrin was converted to the corresponding sulfonyl chloride by treatment with thionyl chloride after conversion to the corresponding triethylammonium salt. The resulting tetra ( $p$-chlorosulfonylphenyl)porphyrin was anchored onto aminopolystyrene. Cobalt was then introduced into the resulting porphyrin polymer to give the sulfonamide-linked polymer IV by a procedure completely analogous to the preparation of the carboxamide-linked polymer $V$ outlined above: The aminopolystyrene used in this work was obtained by nitration of a macroreticular polystyrene $+20 \%$ divinylbenzene resin to the extent of $13.6 \%$ using nitric acid in a mixture of acetic acid and acetic 
anhydride followed by reduction of this nitropolystyrene with stannous chloride in a mixture of hydrochloric acid and acetic acid. Although we do not yet have complete analytical data on our polymers, simple considerations of color intensity indicate that considerably greater loading of porphyrin units onto the polystyrene has been achieved in the cases of the sulfonamide- and carboxamide-linked polymers IV and V, respectively, than in the case of the ketone-linked polymer III.

\section{A Polymer-anchored Phosphine Palladium (II) Chloride Catalyst}

Hogeveen and Volger ${ }^{2}$ observed that 1,5-cyclooctadienedichloropalladium(II), $\mathrm{C}_{8} \mathrm{H}_{12} \mathrm{PdCl}_{2}$, and trihaptocillylchloropalladium dimer, $\left[\mathrm{C}_{3} \mathrm{H}_{5} \mathrm{PdCl}\right]_{2}$, were effective catalysts for the conversion of quadricy'clane to norbornadiene. Most recently Dauben and Kielbania 25 observed that $\left[\left(\mathrm{C}_{6} \mathrm{H}_{5}\right)_{2} \mathrm{P}\right]_{2} \mathrm{PdCl}_{2}$ was an effective catalyst for the conversion of the tricycloheptane $\mathrm{VI}$ to the methylenecyclohexere $\mathrm{VII}$. These observations suggested that a polymer-anchored palladium (II) chloride complex of diphenylphosphinated polystyrene might be an effective catalyst for the conversion of quadricyclane to norbornadiene. We therefore investigated the preparation of such a polymer-anchored phosphine palladium (II) chloride catalyst.
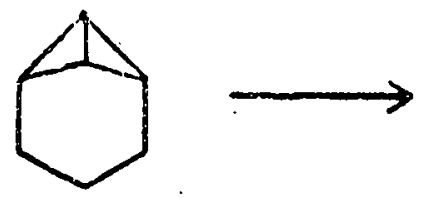

VI

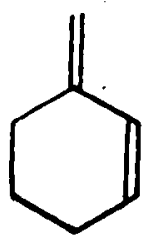

VII

Macroreticular polystyrene beads were diphenylphosphinated by treatment with n-butyllithium followed by treatment with diphenylchlorophosphine. ${ }^{26}$ Palladium (II) chloride was complexed with this polymer by stirring in acetonitrile solution. The resulting lemon yellow beads were an active catalyst for the conversion of quadricyclane to norbornadiene. Two independent samples of beads prepared by this general method gave the following elemental analyses: Sample I: $\mathrm{Pd}, 0.70 \% ; \mathrm{P}, 0.28 \% ; \mathrm{Cl}, 0.39 \%$, Sample II: $\mathrm{Pd}, 1.1 \%$; $P, 0.97 \% ; \mathrm{Cl}, 1.08 \% ; \mathrm{N}, 0.026 \%$. These analytical data are insufficient to define an exact structure for this polymer. However, the absence of significant amounts of coordinated acetonitrile is indicated by the low nitrogen analysis. Sample II has a considerably higher phosphine loading on the polystyrene but a smaller percentage of palladium-complexed phosphorus atoms. 


\section{Quantitative Kinetic Studies}

Experimental Method

About $0.1 \mathrm{~g}$. of the polymer-anchored ratalyst was treated with 10.0 or $20.0 \mathrm{ml}$. of $1.00 \mathrm{M}$ quadricyclane in benzene or xylene containing $0.25 \mathrm{M}$ or $0.50 \mathrm{M}$ of benzene, ethylbenzene, or xylene as an internal gas chromatography standard. The reaction temperature was controlled by an external bath thermostated at $30 \pm 0.1^{\circ}$. Aliquots $(10$ to 40 microliters) of the reoction mixture were withdrawn at 5 minute intervals (measured to $+0.1 \mathrm{~min}$.), diluted to $1.0 \mathrm{ml}$. with pentane, and analyzed by gas chromatography using a $1 / 8 " 8^{\prime \prime} 6^{\prime}$ or $10^{\prime} \times 7.8 \%$ GE SF-96 on Chromosorb W column with a $60 \mathrm{ml} . / \mathrm{min}$. nitrosen flow and a flame ionization detector. Concentrations, were determined by the peak area ratios of quadricyclane to the internal standard compared to the ratio at zero time and $1.00 \mathrm{M}$ quadricyclane concentration. After euch run the polymer was washed for at least 10 minutes each of three times with fresin xylene and dried under vacuum at $60^{\circ}$ before further recycling.

The kinetics of these reactions can be analyzed as pseudo first order reactions since although the quadricyclane concentration is constantly decreasing, the catalyst concentration remains constant throughout the conversion of quadricyclane to norbornadiene. Thus, the observed pseudo first order rate constants $k_{0}$ were obtained from a linear least squares plot of $-\ln$ (concentration) versus the reaction time in minutes. The $k_{0}$ were then converted to a normalized rate constant through the formula $k=k_{0} V /(60 \mathrm{~W})$ where $V$ is the volume of the solution in liters, $W$ is the weight of the catalyst in grams, and the 60 converts the time scale from minutes to seconds. Except as utherwise noted all plots of $-\ln$ (concentration) versus reaction time were approximately linear over 5 to 7 half lives. A rate constant $k_{M}$ was also calculated on the basis of the metal concentration determined by metal analyses on the polymers.

Representative kinetic data obtained in this matter are summarized in Tables 1 and 2 for the cobalt (II) porphyrin and palladium (II) chloride catalysts, respectively. These data include runs obtained by successively recycling the same batch of catalyst in different reactions. Such data are important for the evaluation of the suitability of these attached metal complex catalysts for use in the norbornadiene-quadricyclane photochemical energy storage system where repeated recycling with the same batch of catalyst will occur. 
Results

A. The polystyrene-anchored carboxamide-linked cobalt (II) porphyrin catalysts (Table I)

The rate constants $k$ for the quadricyclane to norbornadiene conversion catalyzed by the polystyrene-anchored carboxamide-linked cobalt (II) porphyrin $V$ were found to decrease with repeated recycling of the same batch (Table la and $I b$ ). This decrease in activity upon recycling was less severe but still significant in the series of runs performed under nitrogen (Table $\mathrm{lb}$ ). A plot of the rate constant $k$ versus the quantity of solution to which the catalyst had been exposed was fairly linear suggesting that some component of the reaction solution caused deactivation of the catalyst.

A possible explanation for the deactivation of the cobalt(II) porphyrin calalysts upon repeated recycling is the oxidation of some of the cobalt (II) to cobalt (III) by traces of oxygen or peroxides. In an attempt to regenerate this deactivated catalyst, it was treated with ferrocene in benzene at $25^{\circ}$ for $2 \mathrm{hr}$. hoping to reduce any cobalt (III) back to cobalt (II) with concurrent oxidation of ferrocene to ferricinium ion. The ferrocene treatment between the fourth and fifth recycles (Table lb) prevented any loss of catalyst activity between these recycles but the catalyst continued to suffer further losses in activity upon further recycling (the sixth and seventh recycles in Table $\mathrm{lb}$ ) when ferrocene treatment was not included. Further limitations of the efficacy of ferrocene as a preventative against catalyst deactivation were indicated by the observation that the catalyst deactivation still occurred when the conversion of quadricyclane to norbornadiene by the polymer-anchored cobalt (II) porphyrin (V) was run in the presence of sufficient dissolved ferrocene to keep all of the cobalt sites on the polymer in the +2 oxidation state (Table Ic).

The conversion rate of quadricyclane to norbornadiene by the polymer-anchored cobalt (II) porphyrin catalyst $\vee$ appeared to be very solvent sensitive. Even the minor solvent churige from benzene to o-xylene (Table (d) resulted in a reproducible retardation of the reaction rate by about $40 \%$.

B. The polystyrene-anchored phosphine palladium (II) chloride catalysts (Table 2)

Recycling studies on the conversion of quadricyclane to norbornadiene using the polystyrene-anchored palladium catalyst containing $0.70 \%$ palladium (Table 2 b) indicate that the initial activity of the fresh catalyst decreases slightly upon the first recycle but that this slightly lowered activity is maintained in the second recycle. However, extensive losses of catalytic activity occurred during the third and fourth recycles.

When a portion of the fresh polystyrene-anchored $0.70 \%$ palladium (II) chlci ice 
catalyst was pre-equilibrated with a solution of norbornadiene and then used for the catalysis of the conversion of quadricyclane to norbornadiene, the observed mate constant (Table 2b) matched most closely that of the untreated palladium catalyst after the first recycle. Thus exposure to norbornadiene has an inhibiting effect on the palladium catalyst. This could arise either from formation of a norbornadiene-palladium complex bound to the polymer and with reduced catalytic activity or to metal leaching by displacement of the polymeric phosphine ligands by rorbornadiene with formation of a soluble palladium complex.

If the first and last portions of the kinetic study on the fresh palladium catalyst (Table $2 b$ ) are analyzed separately, a change is observed in the rate constant during the course of the run. The initivi rate constant is high hut falls to a value matching tinut observed for the firsi recycle by the end of the run. This eliminates the possibility that metal leaching from the support causes the catalyst deactivation, since a rate increase during the course of a run would be expecled if this were the case.

The cause of the drastic rate decreases during the third and fourth recycles of the polystyrene-anchored phosphine palladium (II) chloride catalyst (Table $2 b$ ) is unclear. Possibly upon repeated recycling adventitious oxygen or peroxides oxidizes some of the polymer-anchored phosphorus atoms to phosphine oxide units, which can lead to metal leaching from the polymer.

Comparison of the specific activity per metal atom, ${ }^{k} M$, of the polystyrene-anchored palladium catalysts and the soluble catalyst $\left[\left(\mathrm{C}_{6} \mathrm{H}_{5}\right)_{3} \mathrm{P}\right]_{2} \mathrm{PdCl}_{2}$ indicates that the polystyreneanchored catalyst containing $1.1 \%$ palladium is approximately twice as active as the polystyrene-anchored catalyst containing $0.70 \%$ palladium. whereas the soluble catalyst $\left[\left(\mathrm{C}_{6} \mathrm{H}_{5}\right)_{3} \mathrm{P}\right]_{2} \mathrm{PdCl}_{2}$ is about 1000 times as active as llie polystyrenc-supported catalysts. A major cause of this rate difference is likely to be the slower diffusion of the quadricyclane to the catalyst sites inside the polymer matrix. A very large rate decrease was also observed with polystyrene-anchored $\left(\mathrm{R}_{3} \mathrm{P}\right)_{3} \mathrm{Rh}(\mathrm{CO}) \mathrm{H}$ relative to analogous soluble monomeric rhodium (1) catalysts where rate differences of 10 to 100 were observed which were temperature dependent in the range $140^{\circ}$ to $60^{\circ} .27$

Comparison of the specific activities per metal atom, ${ } M^{\prime}$ of the polyslyreneanchored carboxamide-linked cobalt (II) porphyrin catalysts (Table 1) and the palladium (II) chloride catalysts (Table 2) indicate clearly that the cobalt catalysts are about five times more active for the conversion of quadricyclane to norbornadiene under comparable conditions. However, the relative suitabilities of these two types of catalysts for a practical solar energy storage system based on the norbornadiene-quadricyclane interconversion will depend on a variety of other factors besides their catalytic activities. Thus retention 
of catalytic activity on repeated recycling and freedom from side reactions in the conversion of quadricyclane to norbornadiene are likely to be as important as the initial catalytic activity in the ultimate selection of an attached metal catalyst for a solar energy storage system. Work on both the cobalt and palladium attached metal complex catalysts discussed in this paper is continuing in an effort to develop a catalyst with the properties most suitable for use in a practical solar energy storage system. Meanwhile, the polystyrene-anchored carboxamide-linked cobalt(II) porphyrin $V$ has been successfully incorporated in a laboratory prototype of a solar energy storage system, which is currently undergoing cycling studies.

Acknowledgment: We are indebted to the U.S. Energy Research and Development Administration for partial support of this work under Contract $E(38-1)-893$. We also acknowledge helpfuldiscussions with Professor R.R. Hautala and Professor C. R. Kutal during the course of this project. 


\section{LITERATURE REFERENCES}

1. R. R. Hautala, J. Little, and E. M. Sweet, Solar Energy, in press.

2. H. Hogeveen and H. C. Volger, J. Am. Chem. Soc., 89, 2486 (1967).

3. J. Manassen, J. Catal., 18, 38 (1970).

4. P. G. Gassman and D. S. Patton, J. Am. Chem. Soc., 90, 7276 (1968).

5. P. G. Gassman and T. J. Atkins, J. Am. Chem. Soc., 93, 1042 (1971).

6. P. G. Gassman and T. Nakai, J. Am. Chem. Soc., 93, 5897 (1971).

7. P. G. Gassman and F. J. Williams, J. Am. Chem. Soc., 94, 7733 (1972).

8. P. G. Gassman, G. R. Meyer, and F. J. Williams, J. Am. Chem. Soc., 94, 7741 (1972).

9. P. G. Gassman and T. J. Atkins, J. Am. Chem. Soc., 94, 7748 (1972).

10. R. Noyori, T. Suzuki, Y. Kumagai, and H. Takaya, J. Am. Chem. Soc., 93, 5894 (1971).

11. R. Noyori, T. Suzuki, and H. Takaya, J. Am. Chem. Soc., 93, 5896 (1971).

12. P. G. Gassman, T. J. Atkins, and J. T. Lamb, J. Am. Chem. Soc., 94, 7757 (1972).

13. R. Noyori, T. Odegi, and H. Takaya, J. Am. Chem. Soc., 92, 5780 (1970).

14. R. Noyori, Y. Kumagai, I. Umeda, and H. Takaya, J. Am. Chem. Soc., 94, 4018 (1972).

15. P. Binger, Angew. Chem. Int. Ed., 11, 309 (1972).

16. P. Binger and J. McMeeking, Angew. Chem. Int. Ed., 12, 995 (1973).

17. L. Cassar, P. E. Eaton, and J. Halpern, J. Am. Chem. Soc., 92, 6366 (1970).

18. L. A. Paquette, Accts. Chem. Research, 4, 280 (1971).

19. W. Merk and R. Pettit, J. Am. Chem. Soc., 89, 4788 (1967).

20. J. Wristers, L. Brener, and R. Pettit, J. Am. Chem. Soc., 92, 7499 (1970).

21. H. D. Wilson and R. G. Rinker, J. Catal., 42, 268 (1976).

22. L. D. Rollmann, J. Am. Chem. Soc., 97, 2132 (1975).

23. A. D. Adler, F. R. Longon, J. D. Finarelli, J. Goldmacher, J. Assour, and

L. Korsakoff, J. Org. Chem., 32, 476 (1967).

24. E. B. Fleischer, J. M. Palmer, F. S. Srivastava, and A. Chatteriee, J. Am. Chem. Soc. 93, 3162 (1971).

25. W. G. Dauben and A. Kielbania, Jr., J. Am. Chem. Soc., 94, 3669 (1972).

26. D. C. Evans, M. H. George, and J. A. Barrie, J. Polym. Chem., 12, 247 (1974).

27. R. M. Hanes, Ph.D. Thesis, University of Alabama, 1976. 
TABLE 1

KINETIC DATA FOR THE CONVERSION OF QUADRICYCLANE TO NORBORNADIENE BY THE POLYSTYRENE-ANCHORED CARBOXAMIDE-LINKED COBALT(II) PORPHYRIN CATALYST (V)

Solvent $\quad k\left(\right.$ sec. $\left.^{-1}(g \cdot / 1 .)^{-1}\right) \cdot \quad k_{M}{ }^{\left(\text {sec }^{-1}(g \cdot \text {-atom metal/l. })^{-1}\right)}$

a) Runs in oir

Fresh catalyst

benzene $\quad 1.3 \times 10^{-4}$

1.7

Recycle

benzene $0.9 \times 10^{-4}$

1.2

b) Runs under nitrogen

$\begin{array}{llll}\text { Fresh catalyst } & \text { xylenes } & 1.6 \times 10^{-4} & 2.1 \\ \text { First recycle } & \text { xylenes } & 1.5 \times 10^{-4} & 2.0 \\ \text { Second recycle } & \text { xylenes } & 1.3 \times 10^{-4} & 1.7 \\ \text { Third recycle } & \text { xylenes } & 1.2 \times 10^{-4} & 1.6 \\ \text { Fourth recycle } & \text { xylenes } & 0.90 \times 10^{-4} & 1.2\end{array}$

Treatment with $0.1 \mathrm{M}$ ferrocene in benzene at $25^{\circ}$ for $2 \mathrm{hr}$.

Fifth recycle

xylenes $\quad 0.93 \times 10^{-4}$

1.2

Sixth recycle

xylenes

$0.73 \times 10^{-4}$

1.0

Seventh recycle

xylenes

$0.65 \times 10^{-4}$

0.9

c) Runs under nitrogen in the presence of $0.05 \mathrm{M}$ ferrocene

Fresh cotolyst

benzene. $1.8 \times 10^{-4}$

2.4

First recycle

benzene $\quad 1.5 \times 10^{-4}$

2.0

Second recycle

benzene $\quad 1.4 \times 10^{-4}$

1.8

Third recycle

benzene $1.3 \times 10^{-4}$

1.7

d) Study of solvent effects (average of 2 runs)

Fresh catalyst

benzene $1.8 \times 10^{-4}$

2.4

Fresh catalyst

o-xylene $1.1 \times 10^{-4}$

1.5 


\section{TABLE 2}

KINETIC DATA FOR THE CONVERSION OF QUADRICYCLANE TO NORBORNADIENE BY PALLADIUM(II) CHLORIDE CATALYSTS

$$
\text { Solvent } k\left(\sec ^{-1}(g . / 1 .)^{-1}\right) \cdot \quad k M^{\left(\text {sec }^{-1}(g \cdot \text {-atom metal/1. })^{-1}\right)}
$$

a) $\left[\left(\mathrm{C}_{6} \mathrm{H}_{5}\right)_{3} \mathrm{P}\right]_{2} \mathrm{PdCl} l_{2}$

$$
\begin{array}{llr}
\text { xylene }^{a} & 5.4 \times 10^{-2} & 3780 \\
\text { benzene }^{b} & 1.2 \times 10^{-2} & 80
\end{array}
$$

b) Polystyrene-anchored phosphine palladium (II) chloride with $0.70 \%$ Pd

Fresh catalyst

First nine points

Last nine points

First recycle

Second recycle

Third recycle

Fourth recycle xylene

$2.0 \times 10^{-5}$

$3.1 \times 10^{-5}$

$1.3 \times 10^{-5}$

xylene

xylene

xylene

xylene

xylene
$1.5 \times 10^{-5}$

$1.6 \times 10^{-5}$

$0.41 \times 10^{-5}$

$0.18 \times 10^{-5}$
$1.4 \times 10^{-4}$
0.31

0.47

0.20

0.23

0.24

0.062

0.028

Fresh catalyst ofter norbornadiene equilibration

c) Polystyrene-anchored phosphine palladium(II) chloride with $1.1 \%$ Pd

Fresh eatalyst

benzene

$8.0 \times 10^{-5}$

0.78

- $0.1 \mathrm{M}$ quadricyclane, $2.7 \times 10^{-4} \mathrm{M}$ Pd.

b $0.5 \mathrm{M}$ quadricyclane, $6.2 \times 10^{-5} \mathrm{M}$ Pd. 